\title{
Physical property scaling relationships for polyelectrolyte complex micelles
}

\author{
Alexander E. Marras, Trinity R. Campagna, Jeffrey R. Vieregg*, Matthew V. Tirrell* \\ Pritzker School of Molecular Engineering, The University of Chicago
}

Polyelectrolyte complex micelles (PCMs) are widely used in the delivery of hydrophilic payloads. Their attractive features include an ability to tune physical attributes, which are strongly dependent on the size and chemical structure of each polymer block. Neutral blocks drive nanoscale phase separation while charged blocks control micelle core size and stability. An understanding of physical property behavior controlled by block size is crucial when designing for use in dynamic or biological environments and provides a greater understanding of the physics of polyelectrolyte assembly. In this work, we use small angle x-ray scattering, and light scattering to determine precise scaling behaviors of physical micelle parameters for commonly used polyelectrolytes. We then compare our results to accumulated published data and theory to show strong agreement, suggesting these laws are universal for PCMs.

\section{Keywords}

Polyelectrolyte Complexation; Polyelectrolyte Complex Micelles; Scaling behavior; Micelles; Small Angle X-ray Scattering; Nanoparticles

Introduction

Self-assembled nanoparticles serve an enormous role in nanomedicine as carriers of therapeutic biomolecules, enabling genome editing, vaccine delivery, cancer therapy, and numerous other applications in precision medicine. ${ }^{1}$ Two major classes are lipid nanoparticles, which offer simplicity and familiarity with cell membranes, and polymeric nanoparticles that provide precise control over physical and chemical characteristics and surface modifications for targeting. Polymeric nanoparticles can be a variety of shapes but are most often polymersomes or micelles, assembled from block copolymers that are either amphiphilic or polyelectrolytes. While the aforementioned assemblies are remarkable for many applications, ${ }^{2-6}$ for the purposes of this paper we will focus on micelles assembled from polyelectrolyte block copolymers.

Polyelectrolyte complexes (PECs) self-assemble due to the entropy gain from counterion release when oppositely charged polymers associate. ${ }^{7}$ They are used at multiple scales for purposes including underwater adhesives, ${ }^{8-10}$ early Earth protocell models, ${ }^{11-13}$ structured gels and networks, ${ }^{14,15}$ and nanomedicine. ${ }^{16}$ Block copolyelectrolytes (neutral-charged block copolymers) can phase separate at the nanoscale to form polyelectrolyte complex micelles (PCMs). Due to their hydrophilic and charged nature, PCMs offer delivery capabilities that differ from hydrophobically driven assemblies, as they can sequester different molecules and travel more freely throughout the 
body. This has shown advantageous for delivering charged proteins $,{ }^{17}, 18$ inherently charged nucleic acids ${ }^{18-20}$ or both ${ }^{21}$ into cells and mice including PCMs that cross the blood-brain barrier ${ }^{22}$ and exhibit targeting. ${ }^{23}$

Most often PCMs consist of either a two diblock copolymer system ( $\mathrm{AB}+\mathrm{AC})$, or a diblock and homopolymer system $(\mathrm{AB}+\mathrm{C})$, where $\mathrm{A}=$ neutral block and $\mathrm{B} / \mathrm{C}=$ oppositely charged blocks (Figure 1). In these situations, most PCMs have a core-corona spheroidal morphology, where the core contains the neutralized charged components $(\mathrm{B}+\mathrm{C})$, and the corona is formed from the neutral block (A). Poly(elthylene glycol) (PEG) is commonly used at the neutral component due to its availability and inertness in biological environments, but other net neutral polymers such as polyacrylamide ${ }^{24}$ or zwitterionic polymers ${ }^{25,26}$ have also shown promise. Charged components are generally biopolymers like polypeptides or nucleic acids, synthetic polyelectrolytes, or charged molecules like proteins or drugs. We find the $\mathrm{AB}+\mathrm{C}$ system particularly useful for biomolecule delivery, where the $\mathrm{C}$ component is an unmodified molecule of interest, like an oligonucleotide, and will focus on this arrangement.

In order to fully characterize the shape, size, and structure of these core-corona nanoparticles, multiple scattering and imaging techniques can be used. Full descriptions of polymeric micelle characterization ${ }^{27}$ and our analysis methods ${ }^{28}$ are available elsewhere, and here we briefly describe this process. The size of the core and corona can be determined through a combination of Small Angle X-ray Scattering (SAXS) and Dynamic Light Scattering (DLS). SAXS, as well was Small Angle Neutron Scattering, provides structural information across decades of length simultaneously. In this study, we use SAXS to characterize micelle cores exclusively. Calculating the scattering length density of each material and the solvent shows that DNA contributes the most scattering intensity, followed by the polypeptides, and PEG contributes minimal amounts of scattering (Table S1). The corona is not accounted for in SAXS measurements because the scattering length density of PEG is similar to the solvent. The intensity of SAXS can also provide information about the aggregation number, or number of polymers per micelle. DLS provides the hydrodynamic size for spherical nanoparticles, which includes the corona in our case. Nanoparticle shape can be shown using SAXS, multi-angle light scattering, or transmission electron microscopy (TEM). TEM is a powerful tool that gives an image of only micelle cores, in our case, as the PEG corona does not have sufficient contrast. TEM is advantageous because it requires minimal analysis and is the only technique with a visual representation. However, it is inherently low throughput and requires dehydration or freezing of samples and therefore is used as a supplemental tool for our studies. TEM for a selection of our PCMs is available in Figures S1-S3. Combining multiple complementary characterization methods offers high confidence in results.

Key advantages of polymeric nanoparticles are the ability to control size and to tune distinct features such as internal structure, stability, or surface chemistry. In fact, the efficiency of gene delivery is affected by the length, ${ }^{29}$ charge density, ${ }^{30}$ and architecture ${ }^{31}$ of the charged block and nanoparticle size and morphology affect biodistribution and cellular uptake. Being able to design PCMs with predefined characteristics will remove much of the trial-and-error elements that still exist with PCM assembly, thus our aim is to establish physical scaling behavior through systematic experiments. Design rules exist for amphiphilic micelles in the form of packing parameters based on block length, ${ }^{32,33}$ but these are not analogous to PCMs. PCM thoery ${ }^{34-37}$ predicts that aggregation number $(P)$ increases with $B$ length $\left(\mathrm{N}_{B}\right)$ and decreases with $A$ length $\left(\mathrm{N}_{\mathrm{A}}\right)$ and that core radius $\left(\mathrm{R}_{\text {core }}\right)$ increases with $\mathrm{N}_{\mathrm{B}}$. Some experimental work suggests that hydrodynamic radius $\left(\mathrm{R}_{\mathrm{h}}\right), \mathrm{R}_{\text {core }}$, 
and $P$ increase with increasing $\mathrm{N}_{B}$ and are independent of the length of the $C$ polymer $\left(\mathrm{N}_{\mathrm{C}}\right){ }^{38-40}$ Additionally, $\mathrm{P}$ has been shown to decrease with $\mathrm{N}_{\mathrm{A}}{ }^{41-43}$, all generally agreeable with theory. These developments give insight into scaling behavior, but lack comprehensive data, limiting our understanding of universal scaling for PCMs. Here, we present a systematic experimental study of the relationships between each polymer block length and the resulting micelle structure. Full characterization of PCMs provides scaling laws for $\mathrm{R}_{\text {core }}, \mathrm{R}_{\mathrm{h}}$, and $\mathrm{P}$ with respect to the length of $\mathrm{A}$, $\mathrm{B}$, and $\mathrm{C}$ blocks. We do this for model cationic and anion polypeptides as well as DNA and thoroughly compare our results to existing experimental data and theoretical predictions. These results should simplify the design process, advancing future PCM development for more efficient biomolecule delivery.

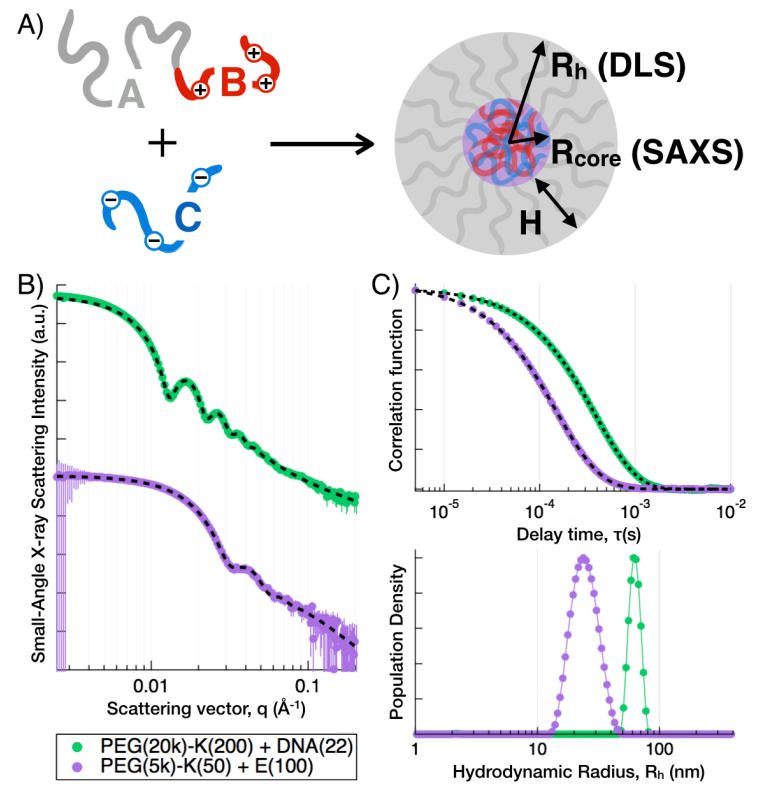

Figure 1. Polyelectrolyte complex micelle (PCM) assembly and characterization. (A) PCMs assembled in this work consist of an $\mathrm{AB}$ block copolymer and $\mathrm{C}$ homopolymer where $\mathrm{A}$ is neutral and $\mathrm{B}$ and $\mathrm{C}$ are oppositely charged. All polymers are hydrophilic and assemble into a core-corona spherical nanoparticle in aqueous solution with low salt. All PCMs were characterized using Small Angle X-ray Scattering (SAXS) and Dynamic Light Scattering (DLS) to determine core radius $\left(R_{\text {core }}\right)$ and hydrodynamic radius $\left(R_{h}\right)$, respectively. The corona thickness $(H)$ is $R_{h}-R_{\text {core }}$ (B) SAXS traces for two PCMs used in this study (green and purple). Modeling SAXS data (black dashed line) provides core size, aspect ratio, and particle size distribution. SAXS data can also be used to find aggregation number. (C) Correlation function data (green, purple) from DLS for the same samples. Fitting DLS data (black dashed lines) provides a distribution of $R_{h}$ for each sample. Two example samles are shown in this figure, PEG(20k)-pLys(200) + 22-nt DNA in green and PEG(5k)-Lys(50) + pGlu(100) in purple. The combination of SAXS and DLS provides complete structural information used to develop experimental scaling laws for physical micelle parameters as a function of the length of each polymer. 
Results

We assembled PCMs using a range of $A, B$, and $C$ polymer lengths $\left(\mathrm{N}_{\mathrm{A}}, \mathrm{N}_{\mathrm{B}}, \mathrm{N}_{\mathrm{C}}\right)$ using poly(ethylene glycol)-block-poly(lysine) (PEG-pLys) as the AB neutral-cationic block copolymer in all cases and studied both single-stranded DNA and poly(glutamic acid) (pGlu) as the "C" anionic homopolymer. These materials reflect commonly used model systems and PCMs used for oligonucleotide delivery and the range of polymer lengths exceeds those that have shown promising for biomolecular applications. We assembled all PCMs by slowly removing high concentration salt through dialysis to ensure a near-equilibrium state ${ }^{28,40}$. We used SAXS and DLS to determine the core size, hydrodynamic size, and aggregation number for all samples. All PCMs were spheroidal, determined via SAXS and confirmed by TEM. We modeled SAXS data using a spheroidal form factor for PCM core structure and a power law at high-q to account for neutralized polymer scattering inside the core. Modeling resulted in PCM core radii in the range of 5-40 nm with a polydispersity indexes between 0-0.1 and aspect ratios between 1 and 2 . Fitting DLS data resulted in hydrodynamic radii in the range of $15-80 \mathrm{~nm}$. Corona thickness was calculated as $\mathrm{H}=\mathrm{R}_{\mathrm{h}}{ }^{-}$ $\mathrm{R}_{\text {core }}$, resulting in $\mathrm{H}$ in the range of 5-50 $\mathrm{nm}$. All characterization results can be found in Table $\mathrm{S} 2$. In order to study physical scaling of PCMs, we chose a systematic set of polymer lengths to assemble a range of PCM sizes.

For each physical attribute, we arranged PCM data into sets where two polymer lengths are fixed and one is variable. For example, Figure 2A shows core radius of PCMs with varying PEG sizes $\left(\mathrm{N}_{\mathrm{A}}\right)$ at pLys lengths $\left(\mathrm{N}_{\mathrm{B}}\right)$ of 30, 50, 100 and 200, all with the homopolymer pGlu(20). In a similar manner, Figure $2 B$ plots $R_{\text {core }} v \mathrm{~N}_{B}$ length for the $3 \mathrm{~N}_{\mathrm{A}}$ sizes, again for homopolymer pGlu(20), and Figure $2 \mathrm{C}$ shows $\mathrm{R}_{\text {core }}$ vs. $\mathrm{N}_{\mathrm{C}}$ length for pGlu. The same plots for pGlu(100), DNA(22), DNA(66), and DNA(88) are in Figures S3-S6. We fit each dataset to a power law, which is shown in text on the plots. Figure 2D shows the power laws calculated for all data sets. We averaged these power laws to determine the scaling law for each polymer length. We used this procedure to determine scaling of core size (Figure 2), number of ion pairs per micelle core (Figure 3), and hydrodynamic size (Figure 4 ) with the length of each polymer $\left(\mathrm{N}_{\mathrm{A}}, \mathrm{N}_{\mathrm{B}}, \mathrm{N}_{\mathrm{C}}\right)$. Power laws from datasets containing less than 3 points were not included in averaging, except for $\mathrm{N}_{\mathrm{C}}$ sets, which show no dependence on polymer length. To the best of our knowledge, this is the first set of complete experimental scaling laws for PCMs.

Core Size. When evaluating core size, we found that $R_{\text {core }}$ decreases slightly with increasing $N_{A}$ with a scaling law of $\mathrm{N}_{\mathrm{A}}^{-0.17 \pm 0.04}$. We observed a strong dependence between $\mathrm{R}_{\text {core }}$ and $\mathrm{N}_{\mathrm{B}}$ of $\mathrm{R}_{\text {core }} \propto$ $\mathrm{N}_{\mathrm{B}}{ }^{0.73 \pm 0.11}$. Conversely, we find $\mathrm{R}_{\text {core }}$ to be independent of $\mathrm{N}_{\mathrm{C}}$. Specifically, we found the scaling law for $\mathrm{R}_{\text {core }}$ to be $\mathrm{N}_{\mathrm{C}}{ }^{-0.05 \pm 0.06}$, which we believe is a power of zero, or complete independence. Additional plots for $\mathrm{R}_{\text {core }}$ are available in Figures S3-S6. 

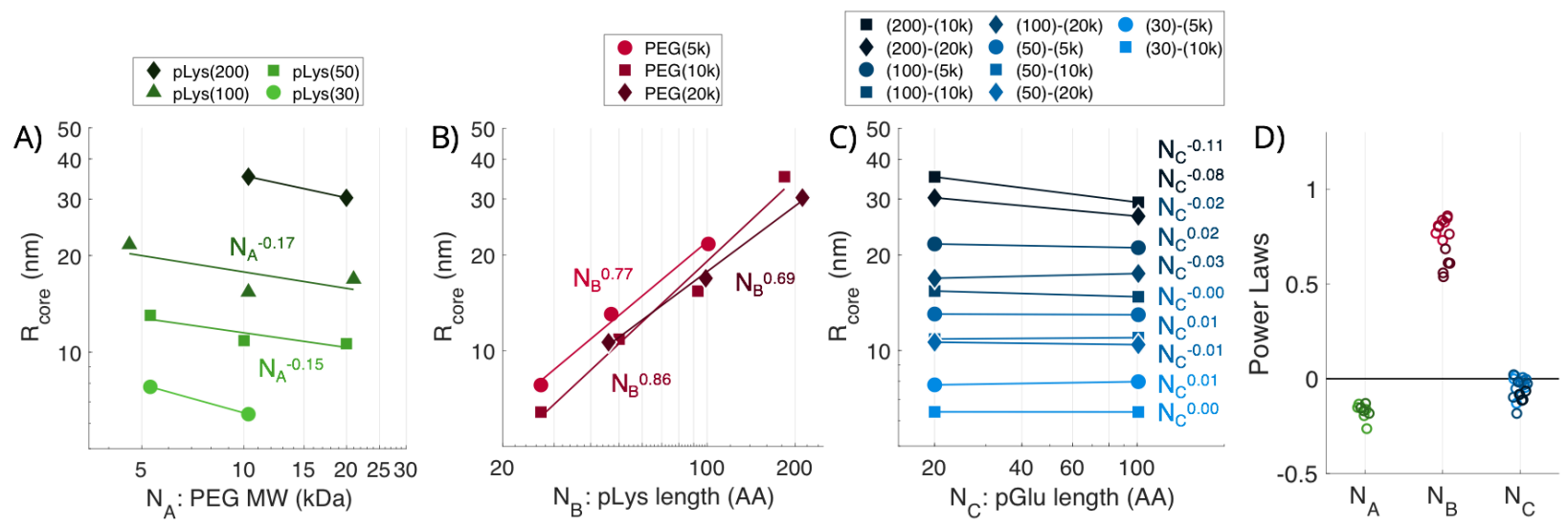

Figure 2. Scaling laws for core radius $\left(R_{\text {core }}\right)$ vs. polymer block length. $R_{\text {core }}$ was determined from modeling SAXS data and was plotted for each polymer length. Power laws were fit for each dataset, shown as lines of the corresponding color. (A-B) show core radius vs. $\mathrm{N}_{\mathrm{A}}$ and $\mathrm{N}_{\mathrm{B}}$, respectively, for PCMs with pGlu(20) homopolymer. (C) shows core radius vs. $\mathrm{N}_{\mathrm{C}}$ for pGlu(20) and pGlu(100). Similar plots for all homopolymers (pGlu(20), pGlu(100), DNA(22), DNA(66), DNA(88)) are in Figures S3-S6. (D) Power laws from all complete datasets were accumulated and shown here. Power laws for each polymer length were averaged to determine the scaling laws of $\mathrm{R}_{\text {core }} \propto \mathrm{N}_{\mathrm{A}}{ }^{-0.17 \pm 0.04}, \mathrm{~N}_{\mathrm{B}}{ }^{0.73 \pm 0.11}, \mathrm{~N}_{\mathrm{C}}^{-0.05 \pm 0.06}$.

Hydrodynamic Size. We followed the scaling law procedure laid out in the previous sections, this time for $R_{h}$, and found that hydrodynamic size increases with $N_{A}$, as expected, with a scaling law of $\mathrm{N}_{\mathrm{A}}{ }^{0.26 \pm 0.16}$. Similarly, $\mathrm{R}_{\mathrm{h}}$ increases as $\mathrm{N}_{\mathrm{B}}{ }^{0.49 \pm 0.18}$ and is independent of $\mathrm{N}_{\mathrm{C}}$, consistent with core size scaling (Figure 3 ). Next, we calculated corona thickness $(H)$ as $H=R_{h}-R_{\text {core }}$ for each PCM and followed our scaling law procedure for $\mathrm{H}$. We found that $\mathrm{H}$ scales with $\mathrm{N}_{\mathrm{A}}{ }^{0.59 \pm 0.23}, \mathrm{~N}_{\mathrm{B}}{ }^{0.23 \pm 0.27}$, and $\mathrm{N}_{\mathrm{C}}{ }^{-0.01 \pm 0.21}$, which we estimate as no effect from either charged block and slightly less than linear scaling with neutral block size. Additional plots for $\mathrm{R}_{\mathrm{h}}$ are available in Figures S7-S9. Plots for $\mathrm{H}$ are available in Figures S10-S12.
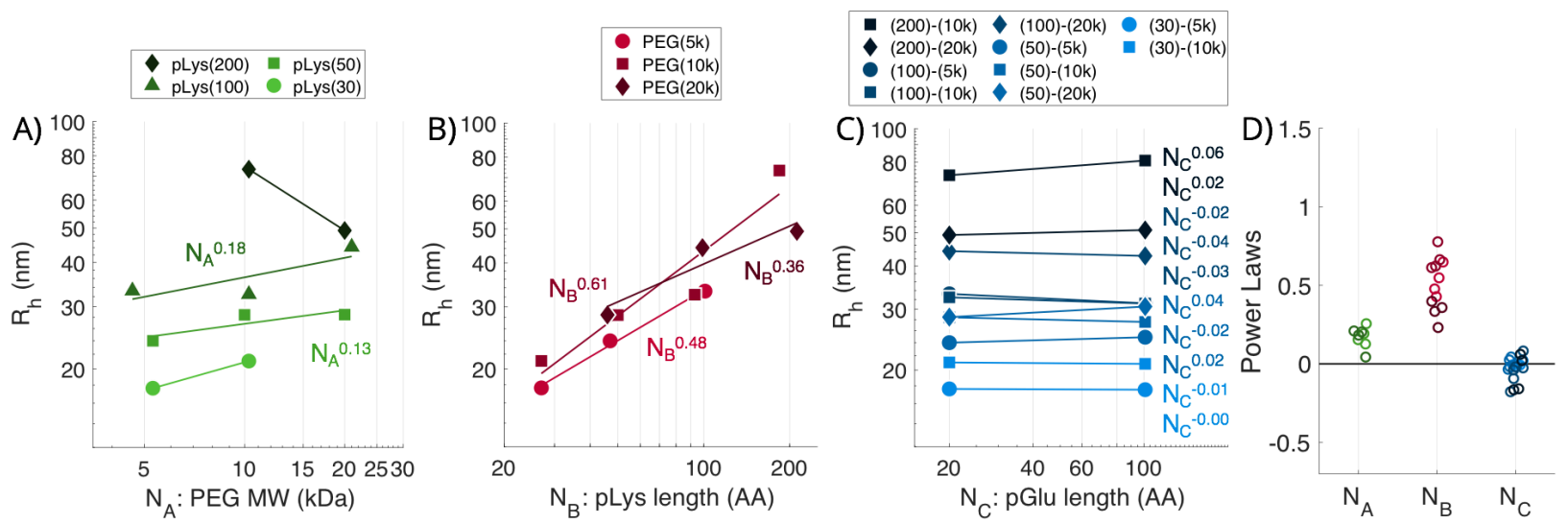

Figure 3. Scaling laws for hydrodynamic radius $\left(R_{h}\right)$ vs. polymer block length, following the same procedure as above. $R_{h}$ was determined from fitting DLS data and was plotted for each polymer length. Power laws were fit for each dataset, shown as lines of the corresponding color. (A-B) show $R_{h}$ vs. $N_{A}$ and $N_{B}$, respectively, for PCMs with pGlu(20) homopolymer. (C) shows $R_{h}$ radius vs. $N_{C}$ for pGlu(20) and pGlu(100). Similar plots for all homopolymers (pGlu(20), pGlu(100), 
DNA(22), DNA(66), DNA(88)) are in Figures S7-S9. (D) Power laws from all complete datasets were accumulated and shown here. Power laws for each polymer length were averaged to determine the scaling laws of $\mathrm{R}_{\mathrm{h}} \propto \mathrm{N}_{\mathrm{A}}{ }^{0.26 \pm 0.16}, \mathrm{~N}_{\mathrm{B}}{ }^{0.49 \pm 0.18}, \mathrm{~N}_{\mathrm{C}}{ }^{0.03 \pm 0.08} \cdot \mathrm{R}_{\mathrm{h}}-\mathrm{R}_{\text {core }}$ gives corona thickness (H). Separate scaling laws were developed for $\mathrm{H}$. H scales with $\mathrm{N}_{\mathrm{A}}{ }^{0.59 \pm 0.23}, \mathrm{~N}_{\mathrm{B}}{ }^{0.23 \pm 0.27}, \mathrm{~N}_{\mathrm{C}}{ }^{-0.01 \pm 0.21}$ and is shown in Figures S10-S12.

Aggregation Number. Aggregation number, or the number of polymers per nanoparticle, can be deduced from SAXS data. This concept is often studied in systems consisting of one polymer (e.g. an $\mathrm{AB}$ block copolymer where B blocks self-assemble) and is a little less clear in our case, because we have two polymers with different length B and C blocks. So instead, we considered the number of ion pairs $\left(\mathrm{n}_{\mathrm{ip}}\right)$ in the core of every micelle. We made the reasonable assumption that the core is entirely charge-neutralized, meaning the number of cationic monomers is equal to the number of anionic monomers, which is equal to $\mathrm{n}_{\mathrm{ip}}$. This also assumes that all polymers are in a micelle, which is a reasonable estimation as the critical micelle concentration of PCMs is thought to be low. ${ }^{24}$ The forward scattering intensity for a dilute solution of spherical particles is proportional to the particle concentration, molecular volume, and scattering contrast (Equation 1). Considering these assumptions, we estimate $\mathrm{n}_{\mathrm{ip}}$ is proportional to $1 / \mathrm{I}(0), \mathrm{R}_{\text {core }}{ }^{6}$, and the square of the scattering length density contrast, $\Delta \rho^{2}$ (Equation 2). Once scaling laws for $\mathrm{n}_{\text {ip }}$ are established, we can use basic assumptions about spherical volume and polymer distribution in solution along with $\mathrm{R}_{\text {core }}$ scaling laws from above to determine relationships for aggregation number and density of each polymer shown in Supplemental Information section S5.

$$
\begin{gathered}
I(q=0) \propto c V^{2} \Delta \rho^{2} \\
n_{i p} \propto \frac{1}{I(0)} R^{6} \Delta \rho^{2}
\end{gathered}
$$

Forward scattering intensity, $\mathrm{I}(\mathrm{q}=0)$ was extrapolated from a linear fit at low-q in a Guinier plot $\left(\ln (\mathrm{I}) \mathrm{vs}^{2}\right)$ for each sample. The scattering length density, $\rho$, was calculated for each material and the solvent in order to determine contrast in SAXS (Table S1). Using $\mathrm{I}(0)$ and $\mathrm{R}_{\text {core }}$ data from SAXS, and following the same procedure from previous sections, we computed scaling relationships for $\mathrm{n}_{\text {ip }}$ as a function of $\mathrm{N}_{\mathrm{A}}, \mathrm{N}_{\mathrm{B}}$, and $\mathrm{N}_{\mathrm{C}}$, and again found a weak negative correlation to $\mathrm{N}_{\mathrm{A}}$, strong positive correlation to $\mathrm{N}_{\mathrm{B}}$, and independence with $\mathrm{N}_{\mathrm{C}}$. Specifically, $\mathrm{n}_{\mathrm{ip}}$ scales as $\mathrm{N}_{\mathrm{A}}^{-}$ ${ }^{0.79 \pm 0.31}, \mathrm{~N}_{\mathrm{B}}{ }^{2.38 \pm 0.41}$, and $\mathrm{N}_{\mathrm{C}}{ }^{-0.21 \pm 0.25}$, as shown in Figure 4. Trends for $\mathrm{n}_{\mathrm{ip}}$ are synergistic with those of $\mathrm{R}_{\text {core }}$ : both decrease as $\mathrm{N}_{\mathrm{A}}$ increases, increase as $\mathrm{N}_{\mathrm{B}}$ increases, and are unaffected by changes in $\mathrm{N}_{\mathrm{C}}$, but the rates of change are more drastic for $n_{i p}$ compared to $R_{\text {core }}$. Furthermore, if the core is neutralized, then $\mathrm{n}_{\mathrm{ip}}$ is equal to the number of charges on the B polymer and the number of charges on the $\mathrm{C}$ polymer. Since we used fully charged $\mathrm{B}$ and $\mathrm{C}$ polymers (one charge per monomer), we can compute aggregation numbers of each polymer as $\mathrm{P}_{\mathrm{AB}}=\mathrm{n}_{\mathrm{ip}} / \mathrm{N}_{\mathrm{B}}$ and $\mathrm{P}_{\mathrm{C}}=\mathrm{n}_{\mathrm{ip}} / \mathrm{N}_{\mathrm{C}}$. Again, by analyzing each polymer length individually while the others remain constant, we determined $\mathrm{P}_{\mathrm{AB}} \propto \mathrm{N}_{\mathrm{A}}{ }^{-0.79 \pm 0.31}, \mathrm{P}_{\mathrm{C}} \propto \mathrm{N}_{\mathrm{A}}{ }^{-0.79 \pm 0.31}, \mathrm{P}_{\mathrm{AB}} \propto \mathrm{N}_{\mathrm{B}}{ }^{1.38 \pm 0.41}, \mathrm{P}_{\mathrm{C}} \propto \mathrm{N}_{\mathrm{B}}{ }^{2.38 \pm 0.41}, \mathrm{P}_{\mathrm{AB}} \propto \mathrm{N}_{\mathrm{C}}{ }^{-0.21 \pm 0.25}, \mathrm{P}_{\mathrm{C}} \propto \mathrm{N}_{\mathrm{C}^{-1.21 \pm 0.25}}$. We estimate within error that $\mathrm{P}_{A B}$ is independent of $\mathrm{N}_{C}$ and $\mathrm{P}_{C}$ decreases linearly with $\mathrm{N}_{C}$. It may seem odd that $N_{A}$ and $N_{B}$ affect $P_{C}$, but they change $R_{\text {core }}$ and if $N_{C}$ is fixed, then $P_{C}$ will change with $\mathrm{R}_{\text {core }}$. Furthermore, monomer and polymer density can be calculated as $\phi_{\mathrm{ip}}=\mathrm{n}_{\mathrm{ip}} / \mathrm{V}_{\text {core }}, \phi_{\mathrm{AB}}=\mathrm{P}_{\mathrm{AB}} / \mathrm{V}_{\text {core }}$, and $\phi_{C}=\mathrm{P}_{\mathrm{C}} / \mathrm{V}_{\text {core }}$. We do not see noticeable changes in the density of ion pairs within the core due to any polymer length, although the propagated error is high (Table S3). In macroscopic polyelectrolyte complexes, polymer density does increase slightly with polyelectrolyte length, ${ }^{44}$ 
but we are not able to determine if this applies for PCMs in our range of polymer lengths. The density of each polymer within the core only appears to decrease approximately linearly with the length of that polymer, as expected for a fixed $\mathrm{n}_{\mathrm{ip}}$. With calibration for absolute intensity in SAXS, a true aggregation number can be found ${ }^{45}$ and should scale relative to these relationships. Full derivations for this section are available in Supplementary Information section S5.
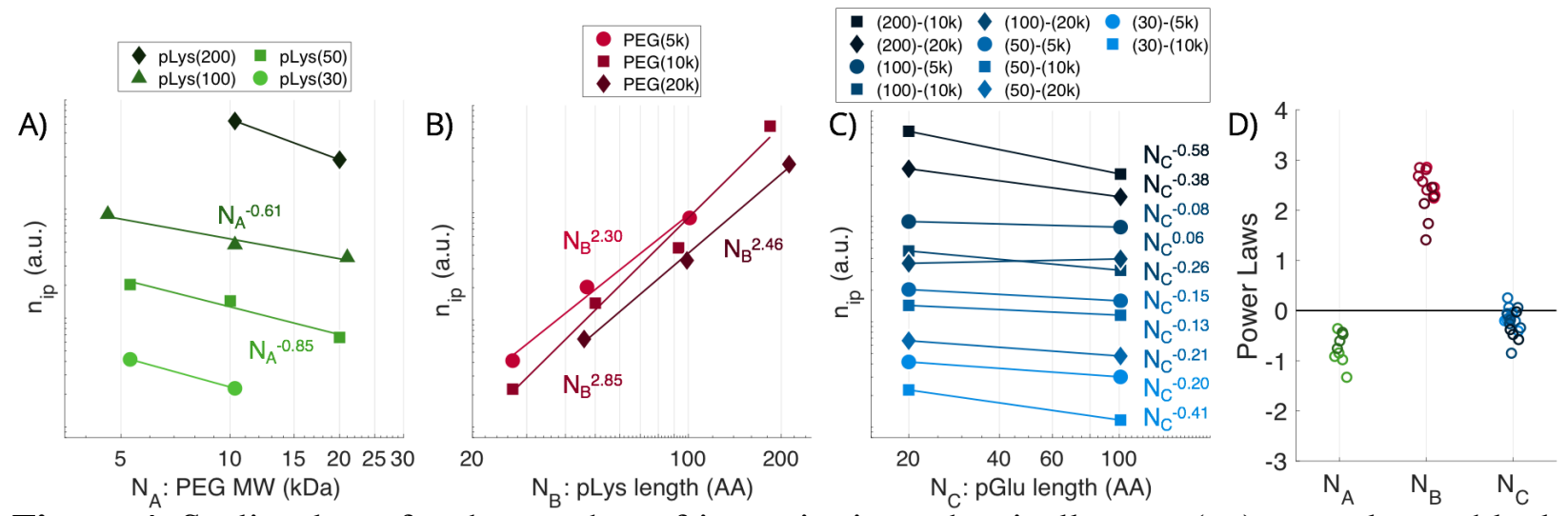

Figure 4. Scaling laws for the number of ion pairs in each micelle core $\left(n_{i p}\right)$ vs. polymer block length, following the same procedure as above. $n_{\text {ip }}$ was determined from from SAXS data (Supplemental Information section S5) and was plotted for each polymer length. Power laws were fit for each dataset, shown as lines of the corresponding color. (A-B) show $n_{i p}$ vs. $N_{A}$ and $N_{B}$, respectively, for PCMs with pGlu(20) homopolymer. (C) shows $\mathrm{R}_{\mathrm{h}}$ radius vs. $\mathrm{N}_{\mathrm{C}}$ for pGlu(20) and pGlu(100). Similar plots for all homopolymers (pGlu(20), pGlu(100), DNA(22), DNA(66), DNA(88)) are in Figures S13-S15. (D) Power laws from all complete datasets were accumulated and shown here. Power laws for each polymer length were averaged to determine the scaling laws of $\mathrm{n}_{\text {ip }} \propto \mathrm{N}_{\mathrm{A}}{ }^{-0.74 \pm 0.31}, \mathrm{~N}_{\mathrm{B}}{ }^{2.38 \pm 0.41}, \mathrm{~N}_{\mathrm{C}}{ }^{-0.21 \pm 0.41}$. Calculating aggregation numbers for each polymer $\left(\mathrm{P}_{\mathrm{AB}}\right.$, $\mathrm{P}_{\mathrm{C}}$ ) as $\mathrm{P}_{\mathrm{AB}}=\mathrm{n}_{\mathrm{ip}} / \mathrm{N}_{\mathrm{B}}$ and $\mathrm{P}_{\mathrm{C}}=\mathrm{n}_{\mathrm{ip}} / \mathrm{N}_{\mathrm{C}}$ we found $\mathrm{P}_{\mathrm{AB}} \propto \mathrm{N}_{\mathrm{A}}{ }^{-0.79 \pm 0.31}, \mathrm{~N}_{\mathrm{B}}^{1.38 \pm 0.41}$ and $\mathrm{P}_{\mathrm{C}} \propto \mathrm{N}_{\mathrm{A}}{ }^{-0.79 \pm 0.31}, \mathrm{~N}_{\mathrm{B}}{ }^{2.38 \pm 0.41}$, $\mathrm{N}_{\mathrm{C}}{ }^{-1.21 \pm 0.25}$.

To summarize these results, we tabulated the power law exponent for each scaling law in Tables 1 and 2. Each scaling law was determined independently of other variables. Equations 3-8 below summarize our findings, showing the experimental scaling behavior we observe for each physical parameter as a function of the polymer lengths that contribute. Scaling laws for $R_{\text {core }}, R_{h}, H$, and $\mathrm{n}_{\mathrm{ip}}$ came directly form data, as shown in Figures 2-4, and scaling laws for $\mathrm{P}_{\mathrm{AB}}$ and $\mathrm{P}_{\mathrm{C}}$ were calculated using the relationships $\mathrm{P}_{\mathrm{AB}}=\mathrm{n}_{\mathrm{ip}} / \mathrm{N}_{\mathrm{B}}$ and $\mathrm{P}_{\mathrm{C}}=\mathrm{n}_{\mathrm{ip}} / \mathrm{N}_{\mathrm{C}}$, as discussed above. These equations include our estimations within error for linear or independent scaling and do not include error, which can be found in Tables 1 and 2 .

$$
\begin{aligned}
R_{\text {core }} & \propto N_{A}^{-0.17} N_{B}^{0.73} \\
R_{h} & \propto N_{A}^{0.26} N_{B}^{0.49} \\
H & \propto N_{A}^{0.59} \\
n_{i p} & \propto N_{A}^{-0.7} N_{B}^{2.4} \\
P_{A B} & \propto N_{A}^{-0.7} N_{B}^{1.4}
\end{aligned}
$$




$$
P_{C} \propto N_{A}^{-0.7} N_{B}^{2.4} N_{C}^{-1}
$$

Table 1. Summary of scaling law exponents for size parameters. Each scaling law is the mean and standard deviation of power laws from all complete datasets.

\begin{tabular}{cccc} 
& $\begin{array}{c}\text { Core Radius } \\
\left(\mathrm{R}_{\text {core }}\right)\end{array}$ & $\begin{array}{c}\text { Hydrodynamic } \\
\text { Radius }\left(\mathrm{R}_{\mathrm{h}}\right)\end{array}$ & $\begin{array}{c}\text { Corona } \\
\text { Thickness }(\mathrm{H})\end{array}$ \\
\cline { 2 - 4 } $\begin{array}{c}\text { Neutral block } \\
\text { length }\left(\mathrm{N}_{\mathrm{A}}\right)\end{array}$ & $-0.17 \pm 0.04$ & $0.17 \pm 0.06$ & $0.59 \pm 0.23$ \\
$\begin{array}{c}\text { Charged block } \\
\text { length }\left(\mathrm{N}_{\mathrm{B}}\right)\end{array}$ & $0.73 \pm 0.11$ & $0.51 \pm 0.16$ & $0.23 \pm 0.27$ \\
$\begin{array}{c}\text { Homopolymer } \\
\text { length }\left(\mathrm{N}_{\mathrm{C}}\right)\end{array}$ & $-0.05 \pm 0.06$ & $-0.03 \pm 0.08$ & $-0.02 \pm 0.21$ \\
& & &
\end{tabular}

Table 2. Summary of scaling law exponents for aggregation parameters. $\mathrm{n}_{\mathrm{ip}}$ scaling laws are the mean and standard deviation of power laws from all complete datasets. $\mathrm{P}_{\mathrm{AB}}$ and $\mathrm{P}_{\mathrm{C}}$ scaling laws are calculated using $\mathrm{n}_{\mathrm{ip}}$ scaling and physical relationships.

\begin{tabular}{c|ccc} 
& $\begin{array}{c}\text { Number of } \\
\text { ion pairs per } \\
\text { core }\left(\mathrm{n}_{\mathrm{ip}}\right)\end{array}$ & $\begin{array}{c}\text { Block copolymer } \\
\text { aggregation } \\
\text { number }\left(\mathrm{P}_{\mathrm{AB}}\right)\end{array}$ & $\begin{array}{c}\text { Homopolymer } \\
\text { aggregation } \\
\text { number }\left(\mathrm{P}_{\mathrm{C}}\right)\end{array}$ \\
\cline { 2 - 4 } $\begin{array}{c}\text { Neutral block } \\
\text { length }\left(\mathrm{N}_{\mathrm{A}}\right)\end{array}$ & $-0.74 \pm 0.31$ & $-0.74 \pm 0.31$ & $-0.74 \pm 0.31$ \\
$\begin{array}{c}\text { Charged block } \\
\text { length }\left(\mathrm{N}_{\mathrm{B}}\right)\end{array}$ & $2.37 \pm 0.41$ & $1.37 \pm 0.41$ & $2.37 \pm 0.41$ \\
$\begin{array}{c}\text { Homopolymer } \\
\text { length }\left(\mathrm{N}_{\mathrm{C}}\right)\end{array}$ & $-0.21 \pm 0.25$ & $-0.21 \pm 0.25$ & $-1.21 \pm 0.25$ \\
& & &
\end{tabular}

In order to provide a visual representation of the data and each scaling law, we gathered all data for each scaling relationship, normalized it using the other scaling laws, and compared the normalized data to the relevant scaling law, as in Figure 5. For example, Figure 2A shows one of five homopolymer groups used to calculate $\mathrm{R}_{\text {core }}$ scaling versus $\mathrm{N}_{\mathrm{A}}$. Power laws for each individual dataset contribute to the $\mathrm{R}_{\text {core }} \propto \mathrm{N}_{\mathrm{A}}$ scaling law, but samples with larger pLys length $\left(\mathrm{N}_{B}\right)$ have larger $R_{\text {core }}$. After calculating $N_{B}$ scaling separately, we used it to normalize the $N_{A}$ data, collapsing $N_{A}$ data for a comparison to the $\mathrm{R}_{\text {core }} \propto \mathrm{N}_{\mathrm{A}}$ scaling law in Figure 5A. Figure 5 shows normalized data compared to our calculated scaling laws for each physical PCM parameter and each polymer length. 

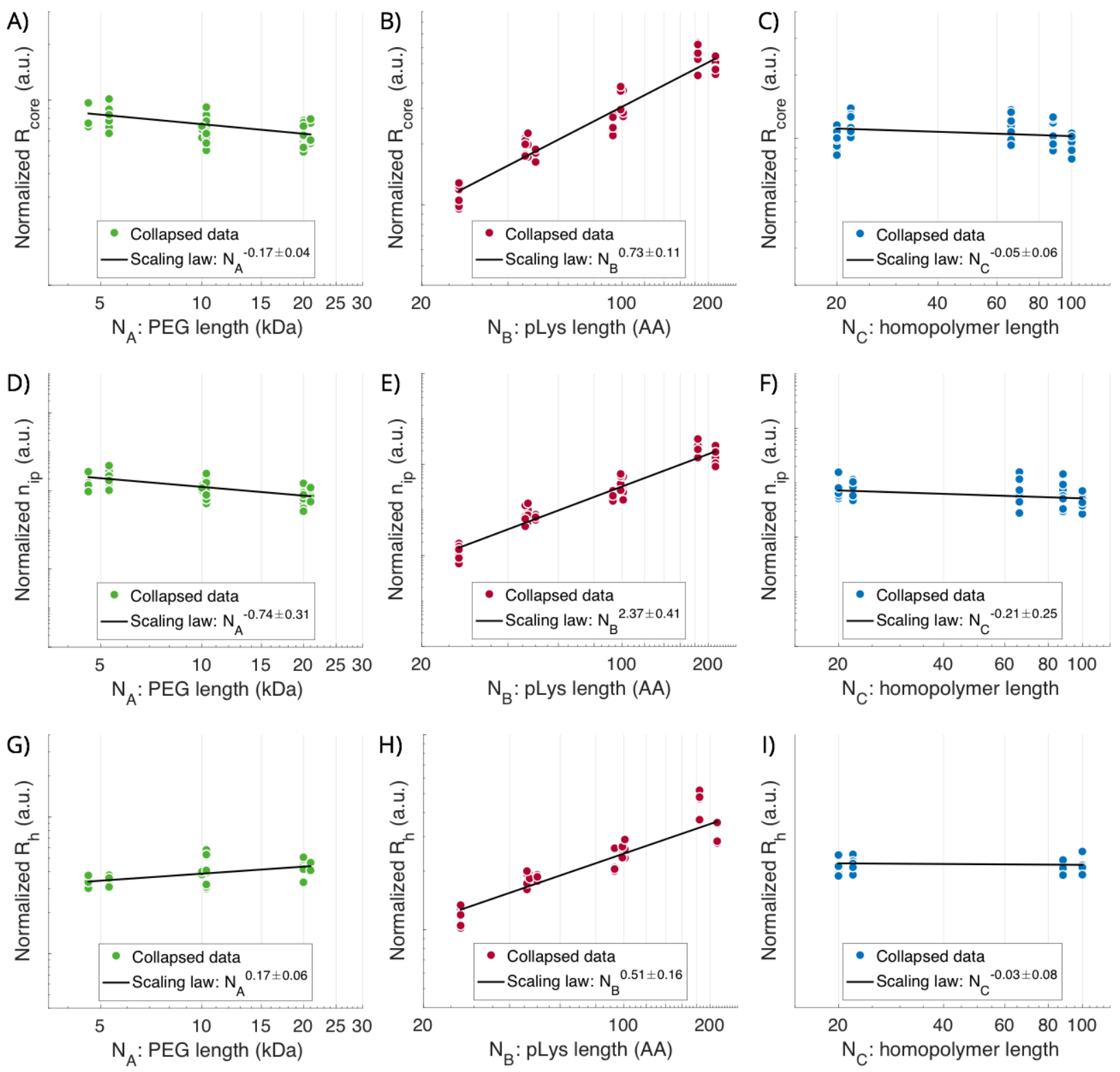

Figure 5. Comparing each scaling law to data normalized by the other scaling laws. (A) Power laws for core radius vs. each polymer length were fit for each dataset. This example shows $\mathbf{R}_{\text {core }}$ vs. $\mathrm{N}_{\mathrm{A}}$ (PEG MW) for four datasets of pGlu(100). (B) Power laws for all datasets for each polymer length were accumulated and a weighted average was applied to determine the scaling law. (C-E) Data were normalized using the other pertinent scaling law(s) and compared with the scaling law of interest. For example, the data shown in (A) were normalized using the $\mathrm{N}_{B}$ scaling law, along with four other plots like (A) for different anionic homopolyers, collapsing $\mathrm{N}_{\mathrm{A}}$ scaling to one line shown in (E), as a visual representation of this work.

\section{Discussion}

The results presented here detail the dependence of micelle size and aggregation number on the size of each polymer included in assembly. PEG-pLys was used as the neutral-cationic block copolymer (AB) for every micelle and single-stranded DNA or pGlu was used as the anionic 
homopolymer (C). We explored lengths from 30-200 charged monomers for the B block, 20-100 charged monomers for the C block, and 5k-20k MW (113-454 neutral monomers) for the A block. We see this range as robust and appropriate for many delivery applications, particularly gene delivery, and representative of a large portion of published literature. In total were fit 166 power laws using a combination of SAXS, DLS and systematic data fitting. We averaged the power laws resulting in the first set of experimental scaling laws for core radius, hydrodynamic radius, corona thickness and the number of ion pairs per PCM core. We also calculated aggregation numbers and polymer densities for each polymer as a function of the length of all three polymer blocks as summarized in Tables 1-2, Equations 3-8, and Table S3.

We observed a strong dependence of micelle core size and aggregation number on the length of the charged block of the block copolymer, while the neutral block is inversely correlated to these parameters. However, the length of the homopolymer has no effect on any size or aggregation number across all of our studies. Block copolymers driving size changes is consistent with our understanding that block copolymers force nanoscale phase separation. When both polyelectrolytes are homopolymers (no neutral block), complexation will instead occur at the micron-scale. The addition of a neutral block limits aggregation to the nanoscale, and we now see that this size is controlled by the architecture of the block copolymer.

PCMs have been researched for decades, but usually only with a small set of polymer lengths in each study, although a few studies use several polymer lengths and include a focus on physical structure. To assess how our scaling laws translate to other polyelectrolyte complex systems, we compared our findings with published data and see substantial agreement for the comparable data. We processed published data in the same way, by normalizing using our scaling laws, and observed data collapsed to the scaling law of interest. Figure $6 \mathrm{~A}-\mathrm{C}$ shows the results for $\mathrm{R}_{\text {core }}$ determined via SAXS of PCMs containing single-stranded DNA + PEG-pLys PCMs and single-stranded DNA + PEG-poly((vinylbenzyl) trimethylammonium) PCMs from two separate studies from our lab ${ }^{39,40}$, showing consistent scaling for core size. Multiple studies from the Cohen Stuart lab ${ }^{38,41,42}$ used DLS and SLS to find $\mathrm{R}_{\mathrm{H}}$ and $\mathrm{P}$, respectively, for a variety of polyelectrolyte systems. This collapsed data spans $>3$ orders of magnitude of $\mathrm{N}_{\mathrm{C}}$, exploring a much wider range than our study, and is consistent with our approximation of homopolymer length independence, up to a critical $\mathrm{N}_{\mathrm{C}}$ where they observe a drastic increase in $R_{h}$. The critical length is $>1000$ units, but is different for each system, as discussed in these studies. ${ }^{38,} 42$ Additionally, (poly(acrylamide)) was used to compare $\mathrm{N}_{\mathrm{A}}$ to $\mathrm{R}_{\mathrm{H}}$ and $\mathrm{P}^{41,42}$, which also fall within our scaling estimations (Figure 6E-F). It is worth noting that this aggregation number was obtained using SLS, while ours is derived from SAXS. Overall, Figure 6 shows that published PCM literature supports our scaling laws, but the available data are sparse and do not cover every law we developed. One notable study ${ }^{46}$ does disagree entirely, stating that $\mathrm{N}_{\mathrm{B}}$ does not affect $\mathrm{R}_{\mathrm{H}}$, conflicting with our findings, and was not included in Figure 6. The reason for this inconsistency is unclear and should be further explored. Additionally, all our PCMs were fabricated using a salt annealing method to ensure equilibrium conformation. Other studies were prepared using other methods which may contribute to moderate noise in Figure 6, although this does not appear significant. 

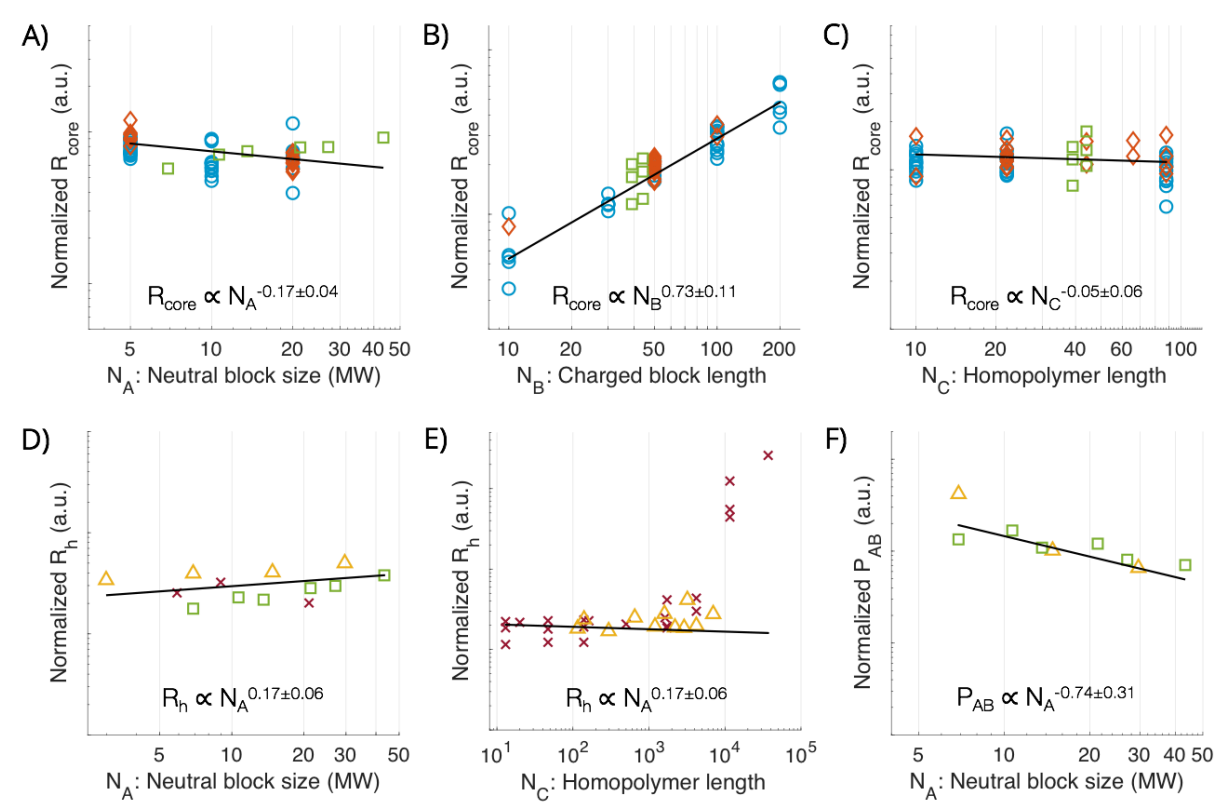

$\triangle$ van der Burgh et al., 2004
$\square$ Voets et al., 2009
$\times \quad$ van der Kooij et al., 2012
$\diamond$ Lueckheide et al., 2018
$\bigcirc$ Marras et al., 2019
- Scaling Law

Figure 6. Comparison to previously published experimental PCM data. We accumulated relevant data for each scaling parameter we studied and normalized them using our scaling laws, following the same process in Figure 5, collapsing to the single scaling law of interest. Markers represent data from published work and black lines are our scaling laws overlayed. We were able to find enough data for six of the nine scaling relationships we studied, all shown here for (A) $R_{\text {core }} \propto N_{A}$, (B) $R_{\text {core }} \propto N_{B}$, (B) $R_{\text {core }} \propto N_{C}$, (B) $R_{h} \propto N_{A}$, (B) $R_{h} \propto N_{C}$, (B) $P_{A B} \propto N_{A}$. Accumulated data ${ }^{38-42}$ represents multiple polymer chemistries from both synthetic polymer and biopolymers, suggesting that these relationships are somewhat universal.

Theorists have studied polymer assembly scaling laws for decades, often for hydrophobically driven assemblies of an amphiphilic polymer solution ${ }^{47-50}$, or for charged-hydrophobic block copolymers ${ }^{47,51}$. Recent work expanded this to hydrophilic polyelectrolyte assembly developing similar theories to our experimental work presented here. Rumyantsev et al.$^{35}$ predicts theoretical scaling for PCMs in the star-like and crew-cut regimes, where star-like PCMs are defined by $\mathrm{R}_{\text {core }}<<\mathrm{H}$ and crew-cut PCMs have $\mathrm{R}_{\text {core }}>>H$. Our PCMs are between these two regimes, as $\mathrm{R}_{\text {core }} / \mathrm{H}$ is between 0.5 and 1.2 for the majority of our samples. Rumyantsev et al.'s predictions are also slightly dependent on solvent, and we are treating ours as a "good" solvent based on previous literature ${ }^{52,53}$, or $v=0.588$ for this theory. For our situation, they predict that $R_{\text {core }}$ scales with $\mathrm{N}_{\mathrm{A}}$ to a power between 0 and -0.54 and $\mathrm{N}_{\mathrm{B}}$ between 0.8 and 2. Likewise, they predict $\mathrm{H}$ scaling with $\mathrm{N}_{\mathrm{A}}$ between 0.588 and 0.81 and with $\mathrm{N}_{\mathrm{B}}$ between 0.165 and 0 , consistent with predictions by Kramarenko et al. ${ }^{36}$ and Borisov and Zhulina. ${ }^{37}$ Lastly, for $\mathrm{P}_{\mathrm{AB}}$, both groups predict an $\mathrm{N}_{\mathrm{A}}$ exponent between 0 and -1.62 and $\mathrm{N}_{\mathrm{B}}$ between 0.8 and 2. For each law, the limits represent predictions for the star-like regime followed by the crew-cut regime. Our PCMs are between these limits and our experimental scaling laws (Tables 1-2, Equations 3-8) are consistent with all these predictions. A full comparison of our results to theory is shown in Table 3 for the common variables, with theoretical predictions for star-like PCMs in the first column, our experimental scaling laws in the second column, and theoretical predictions for crew-cut PCMs in the right column. The theoretical equations shown are from Rumyantsev et al..$^{35}$ and are consistent with earlier theory. ${ }^{36,37}$ The PCMs 
we made are between star-like and crew-cut and our results fall between the two theoretical limits for every variable.

Table 3. Comparison of our experimental scaling laws to theoretical scaling laws. The scaling laws we developed here fall between the two theoretical limits of star-like $\left(\mathrm{R}_{\text {core }}<<\mathrm{H}\right)$ and crewcut $\left(\mathrm{R}_{\text {core }}>>\mathrm{H}\right)$ PCMs for every parameter. This is consistent with theory, as the PCMs we made have comparable $\mathrm{R}_{\text {core }}$ and $\mathrm{H}$ sizes, meaning they are between star-like and crew-cut.

\begin{tabular}{c|c|c} 
Theory (star-like) s5-37 $^{35}$ & $\begin{array}{c}\text { Our Experimental Results } \\
\text { (between star-like and crew-cut) }\end{array}$ & Theory (crew-cut) ${ }^{35-37}$ \\
\hline$R_{\text {core }} \propto N_{B}^{0.6}$ & $R_{\text {core }} \propto N_{A}^{-0.17} N_{B}^{0.73}$ & $R_{\text {core }} \propto N_{A}{ }^{-0.54} N_{B}$ \\
$H \propto N_{A}{ }^{0.59} N_{B}^{0.17}$ & $H \propto N_{A}^{0.59}$ & $H \propto N_{A}{ }^{0.81}$ \\
$P_{A B} \propto N_{B}^{0.8}$ & $P_{A B} \propto N_{A}{ }^{-0.7} N_{B}^{1.4}$ & $P_{A B} \propto N_{A}{ }^{-1.62} N_{B}{ }^{2}$
\end{tabular}

Developing physical property scaling relationships for PCMs that apply across a range of polymer sizes and chemistries will accelerate the design process for tailored PCMs. Depending on the target, a specific core or corona size may be ideal. The $A B+C$ PCM system is particularly convenient for delivery purposes where the $\mathrm{C}$ component is an unmodified therapeutic nucleic acid, protein, or drug. Our result of $\mathrm{N}_{\mathrm{C}}$ having no impact on micelle structure also makes this system quite versatile, where the physical properties of the carrier can be solely tuned with the AB polymer. Previously there was little direction available towards targeting physical properties in PCM assembly, even though size control has proven crucial for efficient therapeutics. We hope our systematic studies on the science of polyelectrolyte self-assembly will contribute to therapeutics and broader applications of polyelectrolyte complexation.

Experimental Methods

Materials Preparation. Poly(ethylene glycol)-poly(L-lysine hydrochloride) (PEG-pLys) and poly(D,L-glutamic acid) sodium salt (pGlu) were purchased from Alamanda Polymers. PEG-pLys diblock copolymers with lengths of $5 \mathrm{k}-30,5 \mathrm{k}-50,5 \mathrm{k}-100,10 \mathrm{k}-30,10 \mathrm{k}-50,10 \mathrm{k}-100,10 \mathrm{k}-200,20 \mathrm{k}-$ 30, 20k-50, 20k-100, 20k-200 (nomenclature: PEG MW-Lysine degree of polymerization) were used. pGlu lengths were 20 and 100. Actual molecular weight (MW) and degree of polymerization (DP) for each polymer by NMR was provided by the manufacturer and used in all calculations (Table S4). 10\% w/v stock solutions were prepared in Milli-Q water, vortexed for 1 min, and sonicated for $5 \mathrm{~min}$ to solubilize per manufacturer's instructions. Stocks were diluted to $20 \mathrm{mM}$ charge concentration (mols charge/L) prior to micelle preparation. DNA oligonucleotide sequences (Table S5) were designed for minimal self-complementarity ${ }^{54}$. Oligonucleotides were ordered from Integrated DNA Technologies and used without further purification. DNA solutions were resuspended in water at $20 \mathrm{mM}$ charge concentration (mols phosphate/L) prior to use.

Preparation of Polyelectrolyte Complex Micelles. PCMs were prepared using the saltannealing method detailed in Marras et al. ${ }^{28}$ Briefly, the components were mixed in the order of concentrated HEPES buffer, water, block copolymer, polyanion, then concentrated $\mathrm{NaCl}$ solution was added to obtain a final concentration of $2 \mathrm{mM}$ charge concentration of each polyelectrolyte, 1 
$\mathrm{M} \mathrm{NaCl}$, and 10mM HEPES buffer and a $400 \mu \mathrm{L}$ total solution volume in a $1.5 \mathrm{~mL}$ Eppendorf tube. Samples were mixed thoroughly after addition of each polyelectrolyte. The salt concentration was then slowly reduced over $36 \mathrm{~h}$ by step dialysis with a $2000 \mathrm{MWCO}$ membrane dialysis cartridge to a final working concentration of $10 \mathrm{mM}$ HEPES and $50 \mathrm{mM} \mathrm{NaCl}$ in water. All experiments were performed at room temperature.

Small-Angle X-ray Scattering (SAXS). SAXS measurements were made at beamline 12-ID-B of the Advanced Photon Source at Argonne National Laboratory. Glycerol was added to all samples for a final concentration of $1 \%$ by volume to minimize radiation damage. Micelle samples were irradiated in a thin-wall glass capillary flow cell with a photon energy of $14 \mathrm{keV} .30$ consecutive $0.2 \mathrm{~s}$ exposures were collected and screened for evidence of radiation damage. During data collection, solutions were flowed through a stationary quartz capillary cell to maximize the exposed volume and reduce the radiation dose per unit volume. Data was reduced in MATLAB at the beamline. Background subtraction and model fitting were performed using the multi-level modeling macros distributed with the Irena software package ${ }^{55}$ for Igor Pro as described previously. ${ }^{28}$ We use assume a Shulz-Zimm distribution and a rigid spheroid shape factor when modeling SAXS data to gather core radius, aspect ratio, and particle size polydispersity (Table $\mathrm{S} 2$ ). While these are core-shell nanoparticles, core-shell shape factors are not appropriate in this situation because the corona is transparent via SAXS. Forward scattering intensity, $\mathrm{I}(\mathrm{q}=0)$, was extrapolated from a linear fit of a Guinier plot $\left(\ln (\mathrm{I}) \mathrm{vs} \mathrm{q}^{2}\right)$ in the region where $\mathrm{q}_{\max } * \mathrm{R}_{\mathrm{g}}<1.3$. All SAXS data will be uploaded to the Materials Data Facility ${ }^{56}$ for public access.

Dynamic Light Scattering (DLS). DLS measurements were made using a Brookhaven Instruments BI-200SM Research Goniometer System with an incident laser $(\lambda=637 \mathrm{~nm})$ at room temperature. A dust-free decalin bath was used to match the refractive index of glass. The average hydrodynamic radius of scatterers under Brownian diffusion was calculated by the Stokes-Einstein relationship. The correlation function at $90^{\circ}$ was fitted to obtain a size distribution using the Cumulant method ${ }^{57}$ in MATLAB and the Regularized Positive Exponential Sum (REPES) algorithm ${ }^{58}$. Both methods were used to compare fits for monomodal and polymodal samples and to avoid skewed size distributions due to aggregation or contamination. Ultimately the results were similar and the REPES sizes were used for all samples.

Transmission Electron Microscopy (TEM). Cryo TEM samples were flash frozen onto lacey carbon film grids (LC200-CU, Electron Microscopy Sciences, Hatflield, PA, USA) using a Vitrobot $^{\mathrm{TM}}$ (FEI, Hillsboro, OR, USA) and imaged on a FEI Talos TEM (FEI, Hillsboro, OR, USA) at an acceleration voltage of $200 \mathrm{kV}$.

\section{ASSOCIATED CONTENT}

\section{Supporting Information.}

Supplemental information includes supplemental data from TEM, SAXS, and DLS. Fitting results, additional scaling relationship plots, derivation and scaling laws for aggregation number and polymer density, and polymer characterization and also included. 
The following files are available free of charge.

Supplemental_Information.pdf

AUTHOR INFORMATION

\section{Corresponding Author}

*Matthew V. Tirrell. mtirrell@uchicago.edu

*Jeffrey R. Vieregg. jvieregg@uchicago.edu

\section{Author Contributions}

A.M. and J.V. designed the experiments. A.M. and T.C. performed the experiments. A.M. modeled and analyzed the data. A.M. wrote the manuscript. J.V. and M.T. revised the manuscript and guided the project. All authors have given approval to the final version of the manuscript.

\section{Funding Sources}

This work was performed under the following financial assistance award 70NANB19H005 from U.S. Department of Commerce, National Institute of Standards and Technology as part of the Center for Hierarchical Materials Design (CHiMaD). This work used resources of the Advanced Photon Source, a U.S. Department of Energy (DOE) Office of Science User Facility operated for the DOE Office of Science by Argonne National Laboratory under Contract No. DE-AC0206CH11357

\section{ACKNOWLEDGMENT}

We would like to thank Dr. Artem Rumyantsev and Dr. Xiaobing Zuo for incredibly helpful discussions, Dr. Tera Lavoie for assistance with cryo TEM, Alexander Doran for preliminary experiments related to this project, and Dr. Hanne van der Kooij for providing published data used in Figure 6.

\section{ABBREVIATIONS}

$\mathrm{N}_{\mathrm{A}}$, length of neutral block in the block copolymer; $\mathrm{N}_{\mathrm{B}}$, length of charged block in the block copolymer; $\mathrm{N}_{\mathrm{C}}$, length of charged homopolymer. $\mathrm{R}_{\text {core }}$, core radius; $\mathrm{R}_{\mathrm{h}}$, hydrodynamic radius, $\mathrm{H}$, corona thickness; nip, number of ion pairs in a micelle core; $\mathrm{P}_{\mathrm{AB}}$, aggregation number of block copolymer; $\mathrm{P}_{\mathrm{C}}$ aggregation number of homopolymer 


\section{REFERENCES}

1. Mitchell, M. J.; Billingsley, M. M.; Haley, R. M.; Wechsler, M. E.; Peppas, N. A.; Langer, R. Engineering precision nanoparticles for drug delivery. Nat Rev Drug Discov 2020, DOI: 10.1038/s41573-020-0090-8.

2. Acar, H.; Srivastava, S.; Chung, E. J.; Schnorenberg, M. R.; Barrett, J. C.; LaBelle, J. L.; Tirrell, M. Self-assembling peptide-based building blocks in medical applications. Adv Drug Deliv Rev 2017, 110-111, 65-79 DOI: 10.1016/j.addr.2016.08.006.

3. Lee, S. W.; Kim, Y. M.; Cho, C. H.; Kim, Y. T.; Kim, S. M.; Hur, S. Y.; Kim, J. H.; Kim, B. G.; Kim, S. C.; Ryu, H. S.; Kang, S. B. An Open-Label, Randomized, Parallel, Phase II Trial to Evaluate the Efficacy and Safety of a Cremophor-Free Polymeric Micelle Formulation of Paclitaxel as First-Line Treatment for Ovarian Cancer: A Korean Gynecologic Oncology Group Study (KGOG-3021). Cancer Res Treat 2018, 50 (1), 195-203.

4. $\quad$ Shae, D.; Becker, K. W.; Christov, P.; Yun, D. S.; Lytton-Jean, A. K. R.; Sevimli, S.; Ascano, M.; Kelley, M.; Johnson, D. B.; Balko, J. M.; Wilson, J. T. Endosomolytic polymersomes increase the activity of cyclic dinucleotide STING agonists to enhance cancer immunotherapy. Nature Nanotechnology 2019, 14 (3), 269-+.

5. Volpatti, L. R.; Matranga, M. A.; Cortinas, A. B.; Delcassian, D.; Daniel, K. B.; Langer, R.; Anderson, D. G. Glucose-Responsive Nanoparticles for Rapid and Extended Self-Regulated Insulin Delivery. Acs Nano 2020, 14 (1), 488-497.

6. Afsharzadeh, M.; Hashemi, M.; Mokhtarzadeh, A.; Abnous, K.; Ramezani, M. Recent advances in co-delivery systems based on polymeric nanoparticle for cancer treatment. Artif Cell Nanomed B 2018, 46 (6), 1095-1110.

7. Fu, J.; Schlenoff, J. B. Driving Forces for Oppositely Charged Polyion Association in Aqueous Solutions: Enthalpic, Entropic, but Not Electrostatic. J Am Chem Soc 2016, 138 (3), 98090 DOI: $10.1021 /$ jacs.5b11878.

8. Zhao, Q.; Lee, D. W.; Ahn, B. K.; Seo, S.; Kaufman, Y.; Israelachvili, J. N.; Waite, J. H. Underwater contact adhesion and microarchitecture in polyelectrolyte complexes actuated by solvent exchange. Nat Mater 2016, 15 (4), 407-412 DOI: 10.1038/nmat4539.

9. Stewart, R. J.; Wang, C. S.; Shao, H. Complex coacervates as a foundation for synthetic underwater adhesives. Adv Colloid Interface Sci 2011, 167 (1-2), 85-93 DOI: 10.1016/j.cis.2010.10.009.

10. Li, A.; Jia, Y.; Sun, S.; Xu, Y.; Minsky, B. B.; Cohen Stuart, M. A.; Colfen, H.; von Klitzing, R.; Guo, X. Mineral-Enhanced Polyacrylic Acid Hydrogel as an Oyster-Inspired Organic-Inorganic Hybrid Adhesive. ACS Appl Mater Interfaces 2018, 10 (12), 10471-10479 DOI: 10.1021/acsami.8b01082.

11. Fares, H. M.; Marras, A. E.; Ting, J. M.; Tirrell, M. V.; Keating, C. D. Impact of wet-dry cycling on the phase behavior and compartmentalization properties of complex coacervates. Nat Commun 2020, 11 (1), 5423 DOI: 10.1038/s41467-020-19184-z.

12. Keating, C. D. Aqueous phase separation as a possible route to compartmentalization of biological molecules. Acc Chem Res 2012, 45 (12), 2114-24 DOI: 10.1021/ar200294y.

13. Koga, S.; Williams, D. S.; Perriman, A. W.; Mann, S. Peptide-nucleotide microdroplets as a step towards a membrane-free protocell model. Nat Chem 2011, 3 (9), 720-4 DOI: 10.1038/nchem.1110.

14. Krogstad, D. V.; Lynd, N. A.; Choi, S. H.; Spruell, J. M.; Hawker, C. J.; Kramer, E. J.; Tirrell, M. V. Effects of Polymer and Salt Concentration on the Structure and Properties of 
Triblock Copolymer Coacervate Hydrogels. Macromolecules 2013, 46 (4), 1512-1518 DOI: 10.1021/ma302299r.

15. Srivastava, S.; Levi, A. E.; Goldfeld, D. J.; Tirrell, M. V. Structure, Morphology, and Rheology of Polyelectrolyte Complex Hydrogels Formed by Self-Assembly of Oppositely Charged Triblock Polyelectrolytes. Macromolecules 2020, 53 (14), 5763-5774 DOI: 10.1021/acs.macromol.0c00847.

16. Magana, J. R.; Sproncken, C. C. M.; Voets, I. K. On Complex Coacervate Core Micelles: Structure-Function Perspectives. Polymers (Basel) 2020, 12 (9), 1953 DOI: 10.3390/polym12091953.

17. Horn, J. M.; Kapelner, R. A.; Obermeyer, A. C. Macro- and Microphase Separated ProteinPolyelectrolyte Complexes: Design Parameters and Current Progress. Polymers-Basel 2019, 11 (4), DOI: $10.3390 /$ polym11040578.

18. Cabral, H.; Miyata, K.; Osada, K.; Kataoka, K. Block Copolymer Micelles in Nanomedicine Applications. Chemical Reviews 2018, 118 (14), 6844-6892 DOI: 10.1021/acs.chemrev.8b00199.

19. Koji, K.; Yoshinaga, N.; Mochida, Y.; Hong, T.; Miyazaki, T.; Kataoka, K.; Osada, K.; Cabral, H.; Uchida, S. Bundling of mRNA strands inside polyion complexes improves mRNA delivery efficiency in vitro and in vivo. Biomaterials 2020, 261, 120332 DOI: 10.1016/j.biomaterials.2020.120332.

20. Van Bruggen, C.; Hexum, J. K.; Tan, Z.; Dalai, R. J.; Reineke, T. M. Nonviral Gene Delivery with Cationic Glycopolymers. Accounts Chem Res 2019, 52 (5), 1347-1358.

21. Tan, Z.; Jiang, Y. R.; Ganewatta, M. S.; Kumar, R.; Keith, A.; Twaroski, K.; Pengo, T.; Tolar, J.; Lodge, T. P.; Reineke, T. M. Block Polymer Micelles Enable CRISPR/Cas9 Ribonucleoprotein Delivery: Physicochemical Properties Affect Packaging Mechanisms and Gene Editing Efficiency. Macromolecules 2019, 52 (21), 8197-8206 DOI: 10.1021/acs.macromol.9b01645.

22. Min, H. S.; Kim, H. J.; Naito, M.; Ogura, S.; Toh, K.; Hayashi, K.; Kim, B. S.; Fukushima, S.; Anraku, Y.; Miyata, K.; Kataoka, K. Systemic Brain Delivery of Antisense Oligonucleotides across the Blood-Brain Barrier with a Glucose-Coated Polymeric Nanocarrier. Angew Chem Int Ed Engl 2020, 59 (21), 8173-8180 DOI: 10.1002/anie.201914751.

23. Kuo, C. H.; Leon, L.; Chung, E. J.; Huang, R. T.; Sontag, T. J.; Reardon, C. A.; Getz, G. S.; Tirrell, M.; Fang, Y. Inhibition of atherosclerosis-promoting microRNAs via targeted polyelectrolyte complex micelles. Journal of Materials Chemistry B 2014, 2 (46), 8142-8153 DOI: 10.1039/C4TB00977K.

24. Voets, I. K.; de Keizer, A.; Cohen Stuart, M. A. Complex coacervate core micelles. Adv Colloid Interfac 2009, 147-148, 300-18 DOI: 10.1016/j.cis.2008.09.012.

25. Ting, J. M.; Marras, A. E.; Mitchell, J. D.; Campagna, T. R.; Tirrell, M. V. Comparing Zwitterionic and PEG Exteriors of Polyelectrolyte Complex Micelles. Molecules 2020, 25 (11), DOI: $10.3390 /$ molecules25112553.

26. Jackson, M. A.; Werfel, T. A.; Curvino, E. J.; Yu, F.; Kavanaugh, T. E.; Sarett, S. M.; Dockery, M. D.; Kilchrist, K. V.; Jackson, A. N.; Giorgio, T. D.; Duvall, C. L. Zwitterionic Nanocarrier Surface Chemistry Improves siRNA Tumor Delivery and Silencing Activity Relative to Polyethylene Glycol. ACS Nano 2017, 11 (6), 5680-5696 DOI: 10.1021/acsnano.7b01110.

27. Patterson, J.P.; Robin, M.P.; Chassenieux, C.; Colombani, O.; O'Reilly, R. K. The analysis of solution self-assembled polymeric nanomaterials. Chem Soc Rev 2014, 43 (8), 2412-25 DOI: $10.1039 / \mathrm{c} 3 \mathrm{cs} 60454 \mathrm{c}$. 
28. Marras, A. E.; Vieregg, J. R.; Tirrell, M. V. Assembly and Characterization of Polyelectrolyte Complex Micelles. J Vis Exp 2020, (157), e60894 DOI: 10.3791/60894.

29. Holley, A. C.; Parsons, K. H.; Wan, W. M.; Lyons, D. F.; Bishop, G. R.; Correia, J. J.; Huang, F. Q.; McCormick, C. L. Block ionomer complexes consisting of siRNA and aRAFTsynthesized hydrophilic-block-cationic copolymers: the influence of cationic block length on gene suppression. Polymer Chemistry 2014, 5 (24), 6967-6976 DOI: 10.1039/c4py00940a.

30. Parsons, K. H.; Holley, A. C.; Munn, G. A.; Flynt, A. S.; McCormick, C. L. Block ionomer complexes consisting of siRNA and aRAFT-synthesized hydrophilic-block-cationic copolymers II: the influence of cationic block charge density on gene suppression. Polymer Chemistry 2016, 7 (39), 6044-6054 DOI: 10.1039/c6py01048b.

31. Tan, Z.; Jiang, Y.; Zhang, W.; Karls, L.; Lodge, T. P.; Reineke, T. M. Polycation Architecture and Assembly Direct Successful Gene Delivery: Micelleplexes Outperform Polyplexes via Optimal DNA Packaging. J Am Chem Soc 2019, 141 (40), 15804-15817 DOI: $10.1021 /$ jacs.9b06218.

32. Holder, S. J.; Sommerdijk, N. A. J. M. New micellar morphologies from amphiphilic block copolymers: disks, toroids and bicontinuous micelles. Polymer Chemistry 2011, 2 (5), 1018-1028 DOI: $10.1039 / \mathrm{c} 0$ py00379d.

33. Israelachvili, J. N.; Mitchell, D. J.; Ninham, B. W. Theory of Self-Assembly of Hydrocarbon Amphiphiles into Micelles and Bilayers. Journal of the Chemical Society-Faraday Transactions Ii 1976, 72, 1525-1568 DOI: DOI 10.1039/f29767201525.

34. Nagarajan, R.; Ganesh, K. Block Copolymer Self-Assembly in Selective Solvents Spherical Micelles with Segregated Cores. J Chem Phys 1989, 90 (10), 5843-5856 DOI: 10.1063/1.456390.

35. Rumyantsev, A. M.; Zhulina, E. B.; Borisov, O. V. Scaling Theory of Complex Coacervate Core Micelles. Acs Macro Lett 2018, 7 (7), 811-816 DOI: 10.1021/acsmacrolett.8b00316.

36. Kramarenko, E. Y.; Khokhlov, A. R.; Reineker, P. Stoichiometric polyelectrolyte complexes of ionic block copolymers and oppositely charged polyions. J Chem Phys 2006, 125 (19), 194902 DOI: 10.1063/1.2387173.

37. Borisov, O.; Zhulina, E. Effect of salt on self-assembly in charged block copolymer micelles. Macromolecules 2002, 35 (11), 4472-4480.

38. van der Kooij, H. M.; Spruijt, E.; Voets, I. K.; Fokkink, R.; Cohen Stuart, M. A.; van der Gucht, J. On the stability and morphology of complex coacervate core micelles: from spherical to wormlike micelles. Langmuir 2012, 28 (40), 14180-91 DOI: 10.1021/la303211b.

39. Marras, A. E.; Vieregg, J. R.; Ting, J. M.; Rubien, J. D.; Tirrell, M. V. Polyelectrolyte Complexation of Oligonucleotides by Charged Hydrophobic-Neutral Hydrophilic Block Copolymers. Polymers-Basel 2019, 11 (1), 83 DOI: 10.3390/polym11010083.

40. Lueckheide, M.; Vieregg, J. R.; Bologna, A. J.; Leon, L.; Tirrell, M. V. Structure-Property Relationships of Oligonucleotide Polyelectrolyte Complex Micelles. Nano Letters 2018, 18 (11), 7111-7117 DOI: 10.1021/acs.nanolett.8b03132.

41. Voets, I. K.; de Vries, R.; Fokkink, R.; Sprakel, J.; May, R. P.; de Keizer, A.; Cohen Stuart, M. A. Towards a structural characterization of charge-driven polymer micelles. Eur Phys J E Soft Matter 2009, 30 (4), 351-9 DOI: 10.1140/epje/i2009-10533-4.

42. van der Burgh, S.; de Keizer, A.; Cohen Stuart, M. A. Complex coacervation core micelles. Colloidal stability and aggregation mechanism. Langmuir 2004, 20 (4), 1073-84 DOI: 10.1021/la035012n. 
43. Voets, I. K.; van der Burgh, S.; Farago, B.; Fokkink, R.; Kovacevic, D.; Hellweg, T.; de Keizer, A.; Cohen Stuart, M. A. Electrostatically driven coassembly of a diblock copolymer and an oppositely charged homopolymer in aqueous solutions. Macromolecules 2007, 40 (23), 84768482 DOI: $10.1021 / \mathrm{ma} 071356 z$.

44. Li, L.; Srivastava, S.; Andreev, M.; Marciel, A. B.; de Pablo, J. J.; Tirrell, M. V. Phase Behavior and Salt Partitioning in Polyelectrolyte Complex Coacervates. Macromolecules 2018, 51 (8), 2988-2995 DOI: 10.1021/acs.macromol.8b00238.

45. Orthaber, D.; Bergmann, A.; Glatter, O. SAXS experiments on absolute scale with Kratky systems using water as a secondary standard. Journal of Applied Crystallography 2000, 33 (2), 218-225 DOI: $10.1107 / \mathrm{s} 0021889899015216$.

46. Harada, A.; Kataoka, K. Effect of charged segment length on physicochemical properties of core-shell type polyion complex micelles from block ionomers. Macromolecules 2003, 36 (13), 4995-5001.

47. Zhulina, E. B.; Borisov, O. V. Theory of Block Polymer Micelles: Recent Advances and Current Challenges. Macromolecules 2012, 45 (11), 4429-4440 DOI: 10.1021/ma300195n.

48. Halperin, A. Polymeric micelles: a star model. Macromolecules 1987, 20 (11), 2943-2946.

49. Noolandi, J.; Hong, K. M. Theory of block copolymer micelles in solution. Macromolecules 1983, 16 (9), 1443-1448 DOI: 10.1021/ma00243a007.

50. Nagarajan, R.; Ganesh, K. Block copolymer self-assembly in selective solvents: Spherical micelles with segregated cores. The Journal of Chemical Physics 1989, 90 (10), 5843-5856 DOI: $10.1063 / 1.456390$.

51. Dan, N.; Tirrell, M. Self-Assembly of Block-Copolymers with a Strongly Charged and a Hydrophobic Block in a Selective, Polar-Solvent - Micelles and Adsorbed Layers. Macromolecules 1993, 26 (16), 4310-4315 DOI: DOI 10.1021/ma00068a037.

52. Sommer, C.; Pedersen, J. S. Temperature Dependence of the Structure and Interaction of Starlike PEG-Based Block Copolymer Micelles. Macromolecules 2004, 37 (5), 1682-1685 DOI: 10.1021/ma0357669.

53. Fischer, V.; Borchard, W. Thermodynamic Properties of Poly(ethylene glycol)/Water Systems. 2. Critical Point Data. The Journal of Physical Chemistry B 2000, 104 (18), 4463-4470 DOI: $10.1021 /$ jp9913214.

54. Vieregg, J. R.; Lueckheide, M.; Marciel, A. B.; Leon, L.; Bologna, A. J.; Rivera, J. R.; Tirrell, M. V. Oligonucleotide-Peptide Complexes: Phase Control by Hybridization. Journal of the American Chemical Society 2018, 140 (5), 1632-1638 DOI: 10.1021/jacs.7b03567.

55. Ilavsky, J.; Jemian, P. R. Irena: tool suite for modeling and analysis of small-angle scattering. Journal of Applied Crystallography 2009, 42 (2), 347-353 DOI: 10.1107/S0021889809002222.

56. Blaiszik, B.; Chard, K.; Pruyne, J.; Ananthakrishnan, R.; Tuecke, S.; Foster, I. The Materials Data Facility: Data Services to Advance Materials Science Research. JOM 2016, 68 (8), 2045-2052 DOI: 10.1007/s11837-016-2001-3.

57. Koppel, D. E. Analysis of Macromolecular Polydispersity in Intensity Correlation Spectroscopy: The Method of Cumulants. The Journal of Chemical Physics 1972, 57 (11), 48144820 DOI: $10.1063 / 1.1678153$.

58. Jakeš, J. Regularized Positive Exponential Sum (REPES) Program - A Way of Inverting Laplace Transform Data Obtained by Dynamic Light Scattering. Collection of Czechoslovak Chemical Communications 1995, 60 (11), 1781-1797 DOI: 10.1135/cccc19951781. 